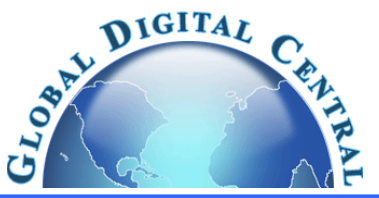

Frontiers in Heat and Mass Transfer

Available at www.ThermalFluidsCentral.org

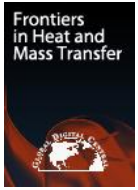

\title{
ASSESSMENT OF TURBULENCE MODELS IN THE PREDICTION OF FLOW FIELD AND THERMAL CHARACTERISTICS OF WALL JET
}

\author{
Arvind Pattamatta ${ }^{\mathrm{a},}$, Ghanshyam Singh ${ }^{\mathrm{b}}$ \\ ${ }^{\text {a }}$ Assistant Professor, Indian Institute of Technology Madras, Chennai 600036, India \\ ${ }^{\mathrm{b}}$ Manager, Agni Biopower Energy Pvt. Ltd., Mohali 160062, India
}

\begin{abstract}
The present study deals with the assessment of different turbulence models for heated wall jet flow. The velocity field and thermal characteristics for isothermal and uniform heat flux surfaces in the presence of wall jet flow have been predicted using different turbulence models and the results are compared against the experimental data of Wygnanski et al. (1992), Schneider and Goldstein (1994), and AbdulNour et al. (2000). Thirteen different turbulence models are considered for validation, which include the Standard k- $\varepsilon$ (SKE), Realizable k- $\varepsilon$ (RKE), shear stress transport (SST), Sarkar \& So (SSA), $v^{2}$-f, Reynolds stress Model (RSM), and Spalart Allmaras (SA) models. Both standard wall function (swf) and enhanced wall treatment (ewt) options available in a commercial CFD solver have been used for near wall treatment for the high Reynolds number models. From the study, it is observed that only a few models could accurately predict the complex flow and thermal features of the heated wall jet. The near wall velocity profile captured using Realizable k- $\varepsilon$ (RKE) with enhanced wall treatment (ewt) shows the best agreement with the experimental data as compared to the other models. Considerable deviation has been observed using SKE with standard wall function ( $s w f$ ) whereas the models of $v^{2}-\mathrm{f}$ show good prediction of velocity and temperature profiles in the near field region. However, the $v^{2}$-f model is found to deviate from the data in the downstream region where the velocity profiles exhibit similarity. In the prediction of heat transfer coefficient, RSM followed by SA and RKE with ewt, is found to be in closer agreement with the experimental data compared to the rest of the models. The computational time required for RSM is substantially higher than that of the other RANS models. Therefore, in the case of gas turbine combustor, since flow field is much more complex, the RKE with ewt would be the preferred choice over the SA model.
\end{abstract}

Keywords: wall jet, heated wall jet, turbulence models, enhanced wall treatment, Realizable k-E (RKE).

\section{INTRODUCTION}

In recent years aircraft engine gas turbine design is driven by the requirement of low emission and high-efficiency. In order to attain higher efficiency, the inlet temperatures and pressures are to be maintained high. On the contrary, the combustion zone temperature is to be as low as possible to minimize the emission level. Therefore, efficient cooling system is a very important aspect of the combustor design. A good cooling system must be able to maintain metal temperatures well within the acceptable limits for the most severe engine operating conditions. To achieve this, wall-jet has been found to be one of the popular methods employed in the cooling of gas turbine combustion chamber liner walls. Wall-jets are also the integral part of many engineering devices. Automobile and aircraft windshield, flow separation control in V/STOL aircraft, and turbine blade cooling are some of the other typical applications wherein wall-jets are used. Launder and Rodi (1981) have given a comprehensive overview of wall-jet flows. The most important feature of this type of flow is that the point at which the shear stress changes sign does not coincide with the position of the zero velocity gradient but lies closer to the wall. The performance of most of the two-equation turbulence models in predicting the spread of plane free jets and mixing layers is found to be satisfactory. However, these models fail to accurately predict near wall flows. The reason for this failure could be the use of wall function and equilibrium and isotropic assumptions behind the development of these models. Predictions for wall jet flows are even more difficult because of the interaction of shear and boundary layers. In the past, Gerodimos and
So (1997) critically assessed some of the existing two-equation models for their ability to predict near-wall behavior and mixing characteristics of the outer and inner layers for the wall jets. They have also evaluated the merits of accounting for anisotropy effects as against to those due to non-equilibrium turbulence. Using the experimental data of Karlsson et al. (1992) and Wygnanski et al. (1992), it was demonstrated by Gerodimos and So (1997) that only the k- $\varepsilon$ model of Sarkar and So (SSA) (1997) could predict the wall jet spread rate and axial decay of maximum velocity within acceptable accuracy. Kumar and Mongia (1999, 2000) have shown that for plane wall jets in external flows, predictions of heat transfer coefficient and film cooling effectiveness using the SSA turbulence model matches well with the test data as compared to the predictions using models of Yang and Shih (1993) and the standard $k-\varepsilon$ model. The applicability of different scaling laws has been critically examined by them and it was shown that the 'law-ofwall' applies only to the viscous sub-layer. The extent of this region is much smaller in the case of wall jet flows than that for the boundary layers. Such flow feature limits the applicability of wall-function for wall-jet flows, which are based on the assumption of local equilibrium and isotropy of turbulence.

The previous studies in the literature, mainly considered the validity of standard $k-\varepsilon$ model and its low Reynolds number variants for wall jet predictions. Also, the performance of these models was assessed for the flow field and the thermal field predictions, separately. Hence, a comprehensive study is required to understand the behavior of turbulence models for heated wall jet flow which takes in to account accuracy in the prediction of both flow field and the thermal

\footnotetext{
*Corresponding author. Email: arvindp@iitm.ac.in
} 
characteristics. The main objective of the present work is to compare the performance of different turbulence models for heated wall jet flow. This paper is a first step toward comprehensive assessment of various state-of-the-art turbulence models including Large-Eddy-Simulation, LES, the results with the latter are planned in the future publications. This is done by carrying out comparison with the experimental measurements of Wygnanski et al. (1992), and Schneider and Goldstein (1994) for the velocity field and with the experimental measurements of AbdulNour et al. (2000) for temperature field. Wygnanski et al. (1992) measured the spatial distribution of mean velocity for various jet Reynolds numbers using Hot-Wire-Anemometer. Schneider and Goldstein (1994) employed LDA technique for the measurement of flow characteristics and provided data for the self-similar velocity profile and jet spread rate. In this paper, the performance of several turbulence models implemented in to a commercial CFD solver is critically assessed for the wall jet flow configuration by comparison with the experimental data in the literature mentioned above.

\section{PROBLEM DESCRIPTION AND SOLUTION METHODOLOGY}

\subsection{Computational domain and boundary conditions}

Experimental data of Wygnanski et al. (1992) and Schneider and Goldstein (1994) are used to validate turbulence models for flow field character and that of AbdulNour et al. (2000) for thermal field. Figure 1 shows the typical wall-jet flow configuration and computational domains corresponding to these three cases used in the present study. For the cold wall-jet configuration, the jet inlet Reynolds number based on the nozzle-exit width and the nozzle-exit velocity is varied from 5000 to 19000 . This is achieved by applying suitable mass flow at the plenum inlet. The rightmost boundary is treated as exit and gradient of all variables is set to zero. As indicated in the Figure 1, constant atmospheric pressure is applied on free boundaries to ensure smooth entrainment of flow from outside. Experimental data of AbdulNour et al. (2000) is used to validate turbulence models for the heated wall-jet case.

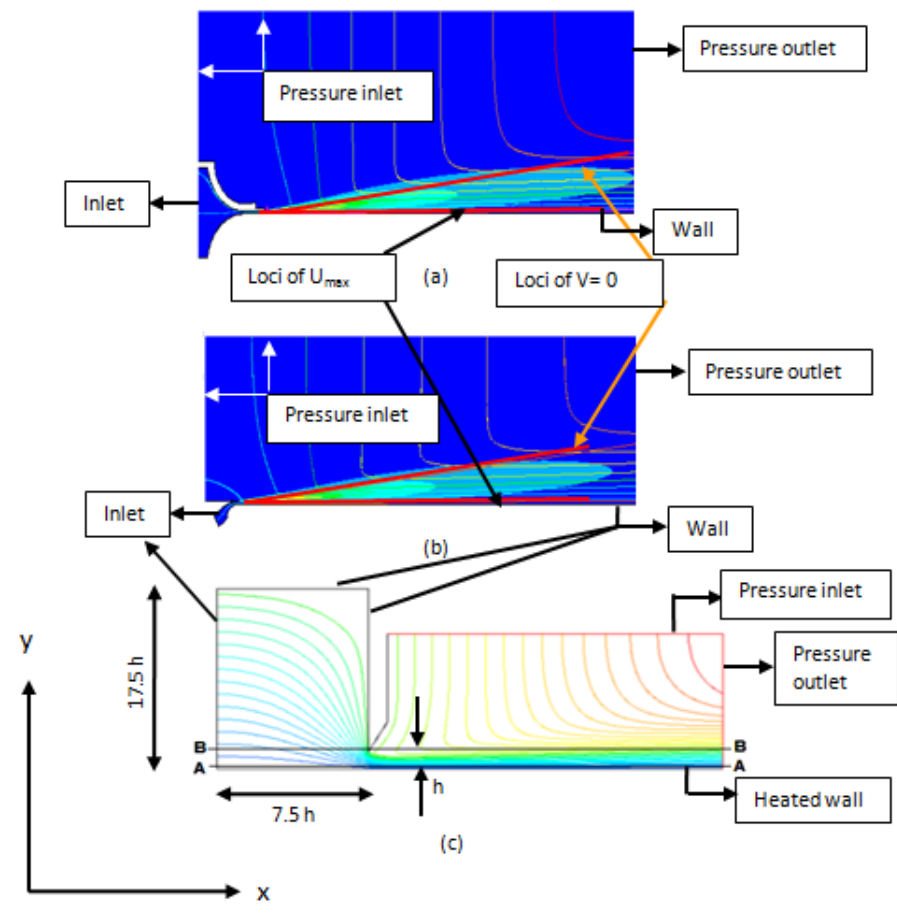

Fig 1. Wall-jet flow configuration for (a) Schneider and Goldstein (1994) (b) Wygnanski (1992) (c) AbdulNour et al. (2000).
The computational domain includes plenum for which dimensions are taken as $7.5 \mathrm{~h} \times 17.5 \mathrm{~h}$ in the axial and transverse directions, respectively. Here $\mathrm{h}$ is the slot width. Mass flow inlet boundary condition was employed at the left most boundary in such a way that the jet inlet Reynolds number based on the nozzle-exit width and the nozzle-exit velocity is 7700 . For heated plate, two different thermal boundary conditions were employed, one as uniform heat flux of 935 $\mathrm{W} / \mathrm{m} 2$ and another one as constant temperature of $318.15 \mathrm{~K}$. The fluid inside the plenum was maintained at temperature of $295.15 \mathrm{~K}$.

\subsection{Governing equations}

For incompressible flows, the Reynolds Averaged Navier Stokes (RANS) equation governing the mean flow along with the equations for $\kappa-\varepsilon$ turbulence model can be written in Cartesian tensor form as:

$\frac{D U_{i}}{D x_{i}}=0$

$\frac{D U_{i}}{D x_{i}}=-\frac{1}{\rho} \frac{\partial P}{\partial x_{i}}+v \frac{\partial^{2} U_{i}}{\partial x_{j} \partial x_{j}}-\frac{\partial \overline{u_{i} u_{j}}}{\partial x_{j}}$

$\frac{D \kappa}{D t}=\frac{\partial}{\partial x_{j}}\left[\left(v+\frac{v_{t}}{\sigma_{\kappa}}\right) \frac{\partial \kappa}{\partial x_{j}}\right]+P_{\kappa}-\varepsilon+D$

$\frac{D \varepsilon}{D t}=\frac{\partial}{\partial x_{j}}\left[\left(v+\frac{v_{t}}{\sigma_{\kappa}}\right) \frac{\partial \varepsilon}{\partial x_{j}}\right]+C_{\varepsilon 1} f_{1} \frac{1}{T_{t}} P_{\kappa}-C_{\varepsilon 2} f_{2} \frac{\widehat{\varepsilon}}{T_{t}}+E$

where

$$
-\overline{u_{i} u_{j}}=2 v_{t} \mathrm{~S}_{\mathrm{ij}}-\frac{2}{3} \kappa \delta_{i j}
$$

$S_{i j}=\left(\partial U_{i} / \partial x_{j}+\partial U_{j} / \partial x_{i}\right) / 2$

$P_{\kappa}=-\overline{u_{i} u_{j}}\left(\frac{\partial U_{i}}{\partial x_{j}}\right)$

The commercial solver ANSYS FLUENT 6.3 has been used for the present study. Thirteen turbulence models, namely those of Standard k- $\varepsilon$ (SKE, Launder and Spalding (1974)), Realizable k- $\varepsilon$ (RKE, Shih et al. (1995)), Reynolds stress model (RSM, Launder et al. (1975)), Shear stress transport (SST, Menter (1994)), Abid (Abid (1991)), AKN (Abe et al. (1994)), CHC (Chang et al. (1995)), LB (Lam and Bremhorst (1981)), LS (Launder and Sharma (1974)), $v^{2}$-f (Durbin (1991)), SSA (Sarkar and So (1997)), YS (Yang and Shih (1993)), and SA (Spalart and Allmaras (1992)) were selected for validation. The SSA model was incorporated in Fluent using a user-defined-function (UDF), whereas all other models are available in the ANSYS FLUENT software. The details of SKE, RKE, RSM, SST, and $v^{2}$-f models are given in References 13,19, 16, 17, and, 6 respectively and not repeated here for the sake of brevity. The constants for these models are taken as default value given in Reference 5. For Low-Reynolds-Number models the details of constants, additional terms, wall boundary conditions and damping functions are given Tables 1,2 and 3 respectively. The simulations for high Reynolds number models (i.e. SKE, RKE and RSM) have been carried out using standard wall function of Launder and Spalding (1973) as well as "enhanced wall treatment" (ewt) approach, available in Fluent. For ewt the grid was refined in such a way that the maximum $y+\approx 1$. The ewt is a two-layer model where laminar-viscosity affected region (i.e. Rey < 200) is modeled using one equation approach of Wolfstein (1969). In one equation model, 
equation for turbulent kinetic energy is same as that in SKE model, but the turbulent viscosity is modeled as:

$$
\mu_{\text {t2Layer }}=\rho C_{\mu} \ell_{\mu} \sqrt{k}
$$

The length-scale appeared in equation is computed based on the approach proposed by Chen and Patel (1988).

$\ell_{\mu}=y c_{l}\left(1-e^{\operatorname{Re}_{y} / A_{\mu}}\right)$

the $\varepsilon$ field is calculated as

Table 1. Low Reynolds number $k-\varepsilon$ models and their model constants.

\begin{tabular}{|c|c|c|c|c|c|c|}
\hline & Model & $\mathrm{C}_{\mu}$ & $\mathrm{C}_{\varepsilon 1}$ & $\mathrm{C}_{\varepsilon 2}$ & $\sigma_{\mathrm{k}}$ & $\sigma_{\varepsilon}$ \\
\hline Abid (1991) & Abid & 0.09 & 1.44 & 1.92 & 1.0 & 1.3 \\
\hline Lam-Bremhorst (1981) & LB & 0.09 & 1.44 & 1.92 & 1.0 & 1.3 \\
\hline Launder-Sharma (1974) & LS & 0.09 & 1.44 & 1.92 & 1.0 & 1.3 \\
\hline Yang-Shih (1993) & YS & 0.09 & 1.44 & 1.92 & 1.0 & 1.3 \\
\hline Abe-Kondoh-Nagano (1994) & $\mathrm{AKN}$ & 0.09 & 1.50 & 1.90 & 1.4 & 1.3 \\
\hline Chang-Hsieh-Chen (1995) & $\mathrm{CHC}$ & 0.09 & 1.44 & 1.92 & 1.0 & 1.3 \\
\hline Sarkar-So (1997) & SSA & 0.096 & 1.44 & 1.92 & 1.0 & 1.43 \\
\hline
\end{tabular}

Table 2. Additional terms and wall boundary conditions for the Low Re. turbulence models.

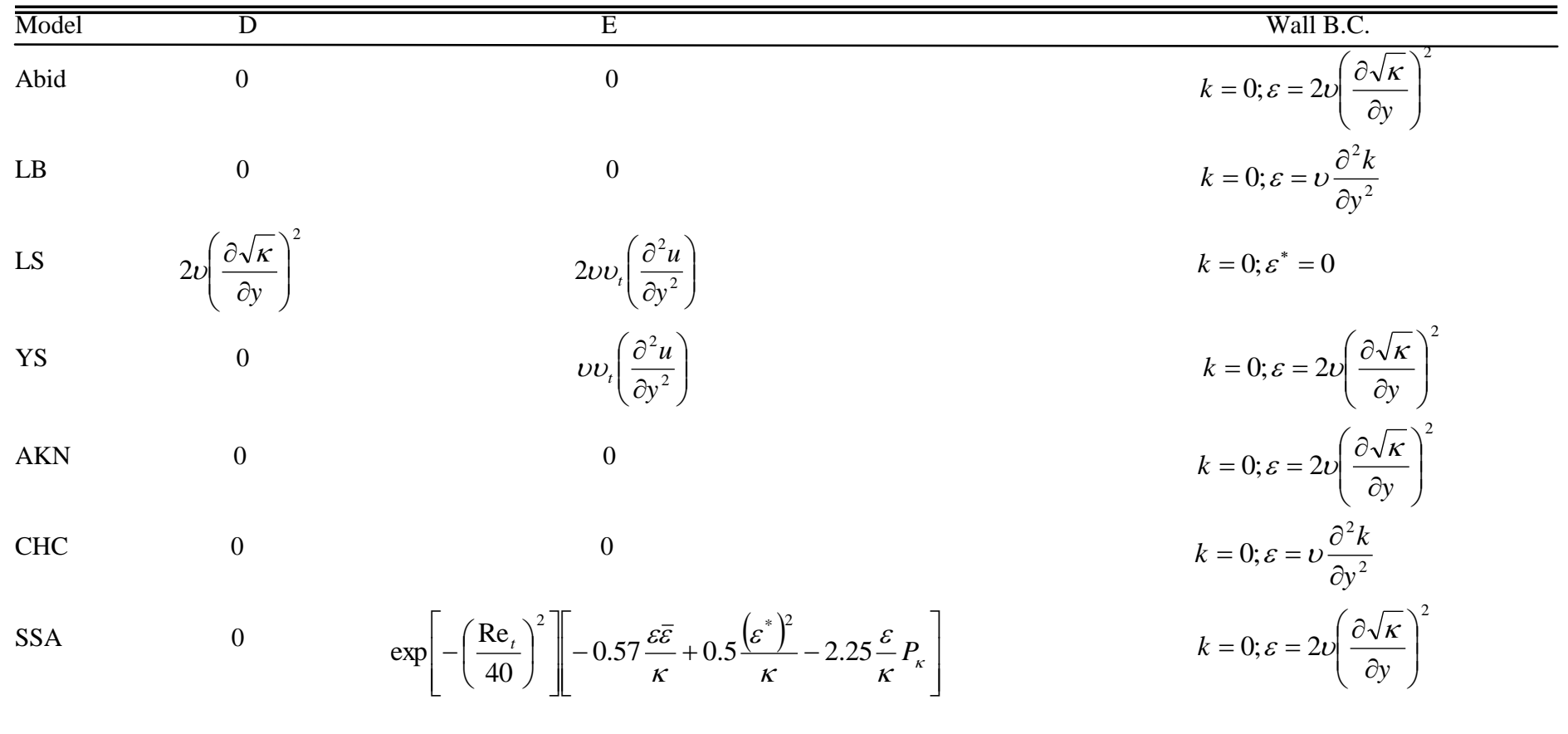

\subsection{Grid sensitivity study}

A detailed grid independence study has been conducted to ensure good solution accuracy. Figure 2(a) and (b) show the results of the grid independence study on the velocity profile for the case of Wygnanski et al. (1992) for Reynolds number of 5000 and on the heat transfer coefficient for the case of AbdulNour et al. (2000) for Reynolds number of 7700, respectively. For the grid "m0", initially, total number of cells was taken as 52416. Subsequently, this grid was adapted in Fluent to see if results are independent of grid refinement. For all the cases, grid sensitivity study was done using RKE with enhanced wall treatment (ewt). The final grid was chosen in such a way that $y+$ for the first grid point from the plate wall is less than five, whereas for the entire

$$
\begin{aligned}
& \varepsilon=\frac{\boldsymbol{k}^{3 / 2}}{\ell_{\varepsilon}} \\
& \ell_{\varepsilon}=y c_{l}\left(1-e^{\operatorname{Re}_{y} / A_{\varepsilon}}\right)
\end{aligned}
$$

Where,

$$
c_{l}=\kappa C_{\mu}^{-3 / 4}, A_{\mu}=70, A_{\varepsilon}=2 c_{l}
$$

Further details are available in References 4 and 5. 
study. In order to ensure that are results are independent of grid refinement, the grids are generated in such a way that the refinement is done within region $\mathrm{AA}$ and BB, as shown in Figure 1(c). Figure 2(c) shows the effect of grid refinement on heat transfer coefficient using realizable $\mathrm{k}-\varepsilon$ model with enhanced wall treatment (ewt) for uniform heat flux B.C. for $\mathrm{Re}=7700$ and compared with the experimental data of AbdulNour et al. (2000). In this figure ' $\mathrm{m} 1$ ' indicates grid distribution of $426 \times 50$ with $y+>50$, ' $\mathrm{m} 2$ ' indicates grid distribution of $426 \times 65$ with $y+\sim 30$, ' $m 3$ ' indicates grid distribution of $426 \times 74$ with $y+\sim 10$ and the fourth grid, ' $\mathrm{m} 4$ ' is generated in such a way that the grid counts in the transverse direction remains same as 74 , whereas $y+$ comes down to approximately value of 0.9 . It is clear from the Figure 2(c) that except for results on coarser grid, ' $\mathrm{m} 1$ ', results for all the other three finer grids are the same. Therefore, grid ' $\mathrm{m} 4$ ', is taken for all high-Reynoldsnumber models with ewt, and for all other low-Reynolds-number model cases. For high Reynolds number models with standard wall-function (swf), grid ' $\mathrm{m} 2$ ', in which $\mathrm{y}+$ was maintained close to 30 is used in the rest of the study.

The convergence criteria for all the models are set to 10-6 for continuity and momentum equations. The total number of iteration required for most of the models varies from 8000 to 9000 iterations. The number of iterations required for RSM is nearly 50000, which is substantially high. The second order upwind scheme is used for the spatial discretization of the convective terms in the governing equations.

Table 3. The damping functions used in the Low Re. models.

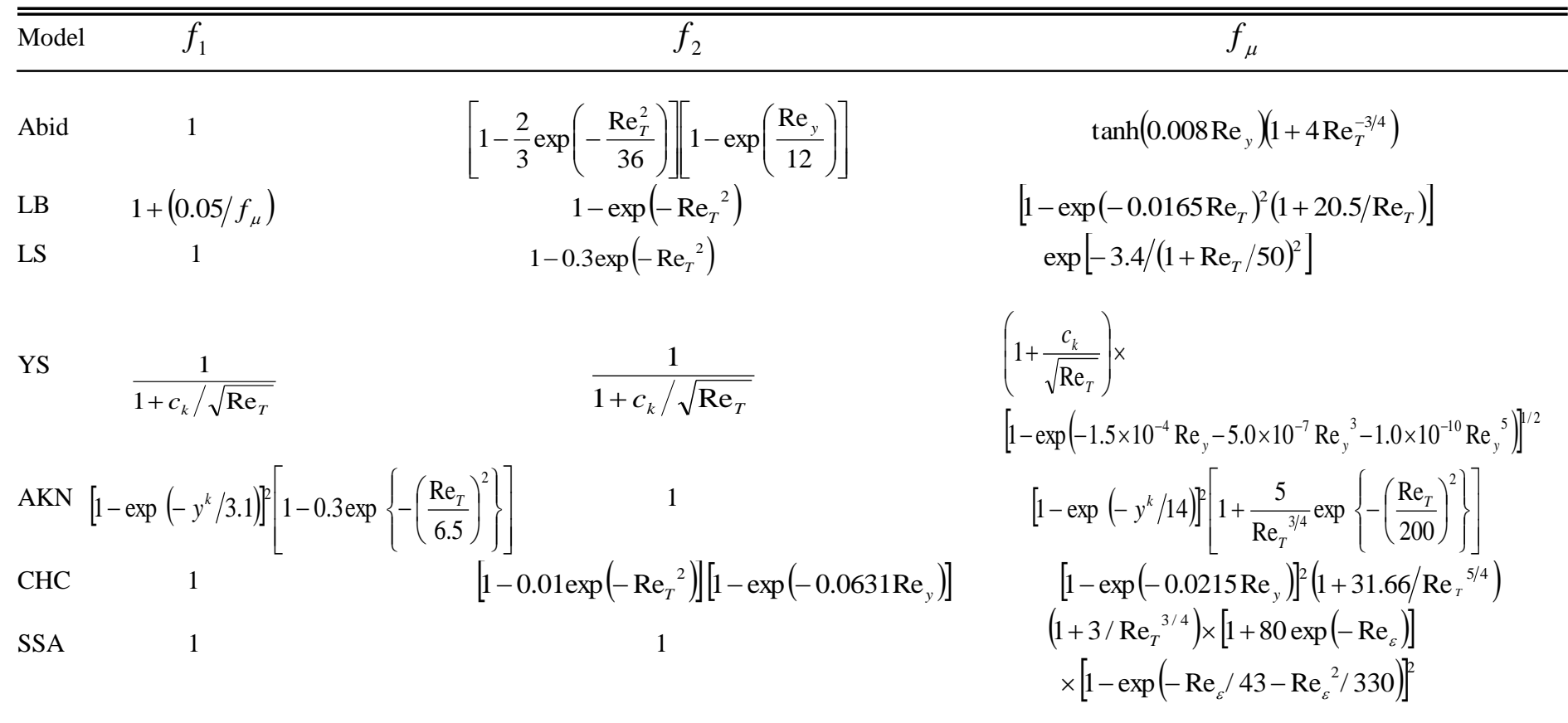

\section{RESULTS AND DISCUSSION}

In this section, for the turbulence models considered, first, the selfsimilar velocity profile, jet spread rate, mean velocity profile in the inner region and applicability of general similarity, proposed by Wygnanski et al. (1992) have been compared with the experimental data. Subsequently, the temperature profiles, thermal boundary layer thicknesss and the heat transfer coefficient predicted by the different turbulence models are compared with that of AbdulNour et al. (2000). The better model is identified based on factors such as good agreement with experimental data and lower computational time.

\subsection{Comparison of Velocity Field}

Figure 3 show the comparison of self-similar velocity profile normalized by the maximum velocity at the same stream wise location for different models with the results of Wygnanski et al. (1992) and Schneider and Goldstein (1994) for Reynolds number of 10000 and 19000. The experimental uncertainty in the measurements for velocity is around 3\% as reported by Schneider and Goldstein (1994). Seven different turbulence models namely Standard k- (SKE), Realizable k(RKE), Reynolds stress model (RSM), Shear stress transport (SST), Sarkar and So (SSA), Spalart and Allmaras (SA) and $\boldsymbol{v}^{2}$-f model $\left(v^{2}-\mathrm{f}\right)$ are chosen for comparison. The standard wall function (swf) is used for near wall treatment with SKE while the enhanced wall treatment (ewt) option is used with RKE and RSM. The results predicted by all the models closely follow the data of Schneider and Goldstein (1994) within the experimental uncertainty level. Results using all the models are in good agreement with the data with a slight deviation observed using RSM_ewt and SA models.

In Figures 4(a-c) the predicted normalized mean velocity profile in the inner or the near wall region of the wall jet is compared with the experimental data of Wygnanski et al. (1992). The results using SKE_swf, RKE_ewt and SST models have been compared against the experimental data for $\mathrm{Re}$ varying in the range of 5000 to 19000, in Figures 4 (a)-(c), respectively. From this figure, it is observed that the results obtained using the different models show a closer agreement to the experimental data for $\mathrm{Re}=5000$ while deviating significantly from the data for $\operatorname{Re}=19000$. The velocity profiles obtained using RKE_ewt gives a better agreement with the experimental data as compared to the other two models. For the sake of comparison, the log law has also been plotted in the figure. As pointed out by Gerodimos and So (1997), except SKE_swf, all other models show considerably small limited log region. Considerable under prediction in the near wall velocity profile has been observed using the RSM_ewt, SSA, and $v^{2}$-f models, which are not shown here.

Figure 5 presents the variation of the turbulent intensity with the wall normal distance along the downstream distance at different axial locations for Reynolds numbers of $5000 \& 19000$, respectively. In this figure results using only RKE_ewt model are presented here, the predictions of the other models are quite similar in nature to that of RKE_ewt. Unlike experimental data the results show a self-similar profile for the turbulent intensity and produces a good agreement with the data of Wygnanski et al. (1992) for Re of 19000. 


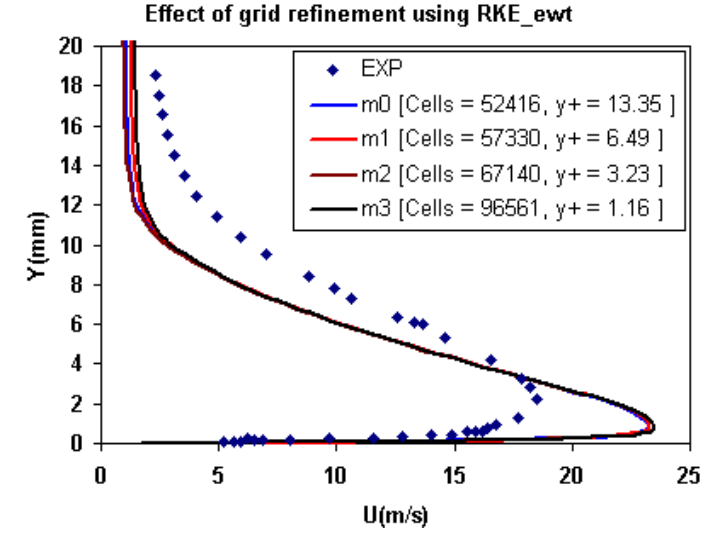

(a)

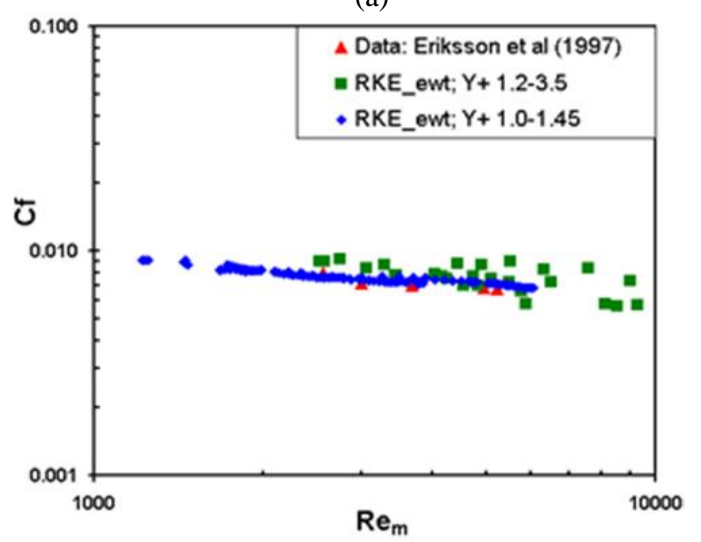

(b)

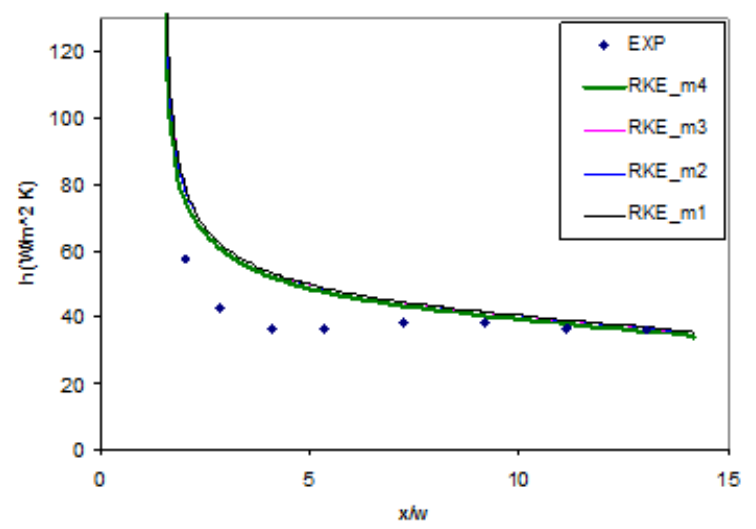

(c)

Fig 2. (a) Effect of grid refinement on self-similar velocity profile for $\operatorname{Re}=5000$ at $\mathrm{X} / \mathrm{s}=20$ (b) Effect of $\mathrm{y}+$ on skin friction coefficient $\operatorname{Re}=5000$ (c) Effect of grid refinement on heat transfer coefficient using RKE with uniform heat flux BC for Re $=7700$.

Figure 6 shows the comparison of the maximum velocity with the downstream distance. The ratio of $(\mathrm{Uj} / \mathrm{Um})^{2}$ is plotted against the normalized downstream distance $(\mathrm{X}-\mathrm{X} 0) / \mathrm{w}$ in order to have a linear profile as the velocity scale is expected to decay approximately as $1 / \mathrm{X} 1 / 2$. The stream wise distance is measured from a virtual origin $\mathrm{X} 0$. It is seen that the results using RKE_ewt and SKE_swf produce a good match with the data whereas RSM_ewt and $v^{2}$-f models over predicts. All other models produce significant under prediction.

In Figure 7, the jet-spread rate predicted by various models is compared with the data of Schneider and Goldstein (1994) for Re of 14000. The RKE_ewt model shows good match, however SKE_swf and RSM_ewt produce significant over prediction in the downstream and rest of the models show under prediction.

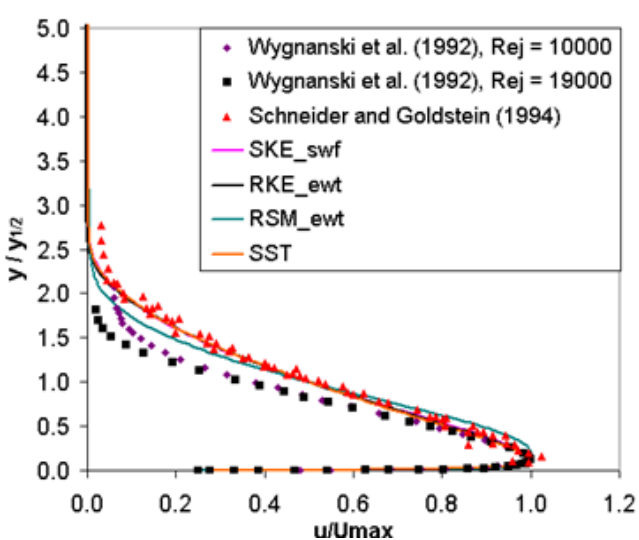

(a)

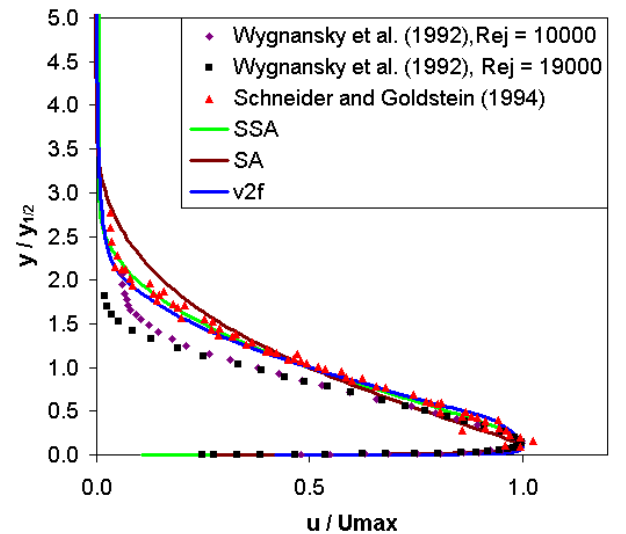

(b)

Fig 3. Comparison of self-similar velocity profiles for different models with the experimental data.

Figures 8 and 9 show the comparison of normalized velocity decay and jet growth, respectively. It has been observed that most of the models show similar trend, therefore in these figures predictions using only RKE_ewt are shown on two different length scales. As suggested by Wygnanski et al. (1992), the data for the Reynolds numbers in range of 5000-19000 have been correlated based on non-dimensional velocity decay $(\operatorname{Umax} \boldsymbol{v} / \mathrm{J})$ and jet spread $(\mathrm{Ym} / 2 \mathrm{~J} / \boldsymbol{v} 2)$ using equations 13 and 14 below and, in Table 4, the correlation parameters Ay, Au, $\mathrm{m}$ and $\mathrm{n}$ for different models are compared for Reynolds number 5000 and 19000.

$$
Y_{m / 2} J / v^{2}=A_{y}\left[X J / v^{2}\right]^{m}
$$

$U_{\max } v / J=A_{u}\left[X J / v^{2}\right]^{n}$

$Y_{m / 2} J / v^{2}=A_{y}\left[\left(X-X_{0}\right) J / v^{2}\right]^{m}$

$U_{\max } v / J=A_{u}\left[\left(X-X_{0}\right) J / v^{2}\right]^{n}$

As shown in Table 4, the exponents for the velocity decay and jet growth are same as estimated by Wygnanski et al. (1992), but constant coefficient differs considerably for different models. However, this deviation for length scale, based on virtual origin is more, specially at low Reynolds number. The agreement in coefficients estimated for SKE_swf, RKE_ewt and RSM_ewt is slightly better as compared to other models, with average value of coefficients using RSM_ewt being closest to data. However, as shown in Figures 6 and 7, jet spread, velocity decay and near wall velocity profile using RSM_ewt does not agree well with experiments. 


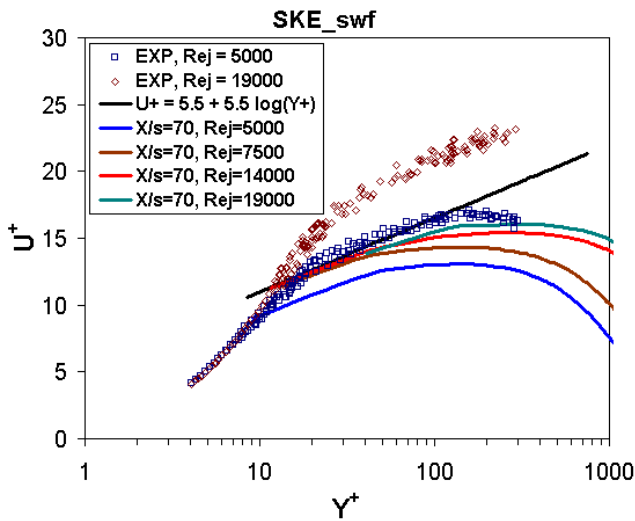

(a)

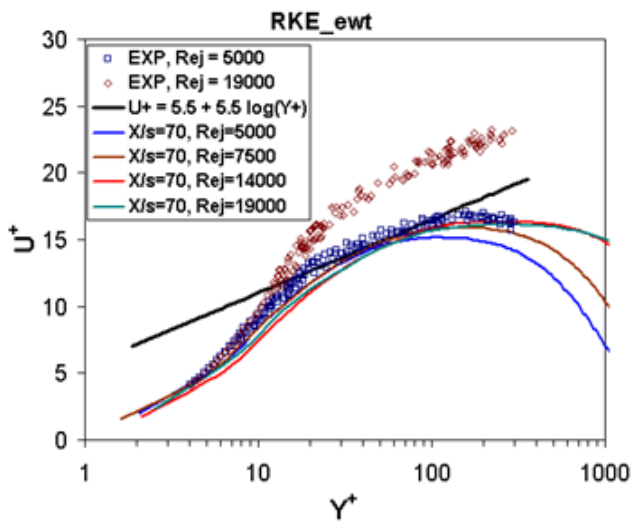

(b)

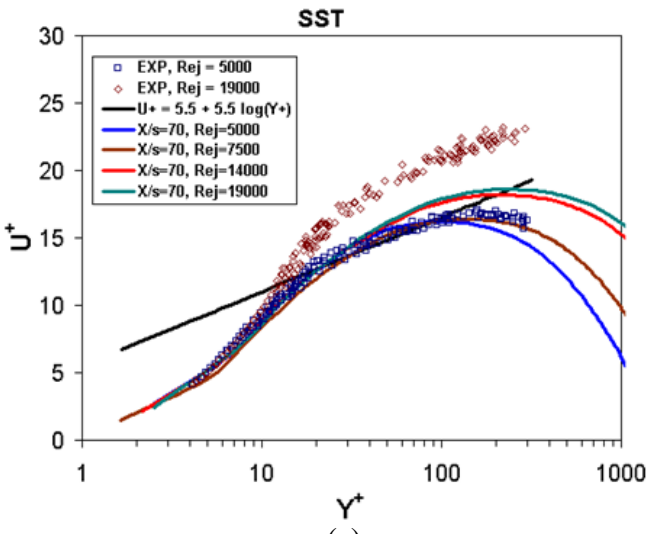

(c)

Fig 4. Comparison of the normalized mean velocity profile in the inner layer of the wall jet for different models.

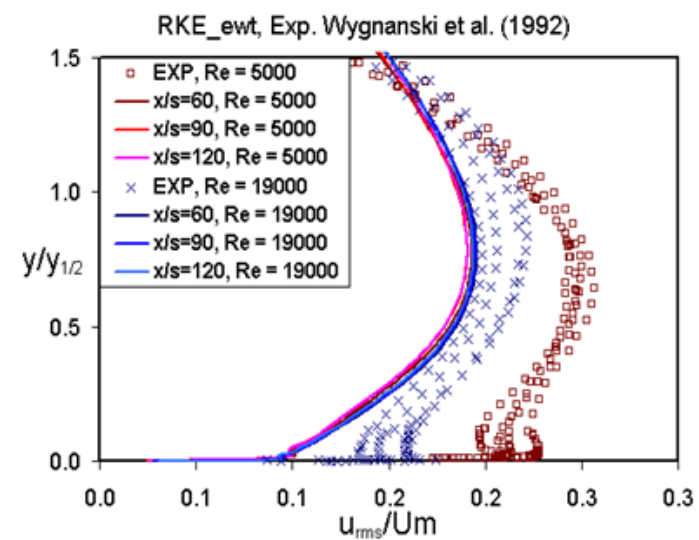

Fig 5. Comparison of the turbulent intensity with experiments.

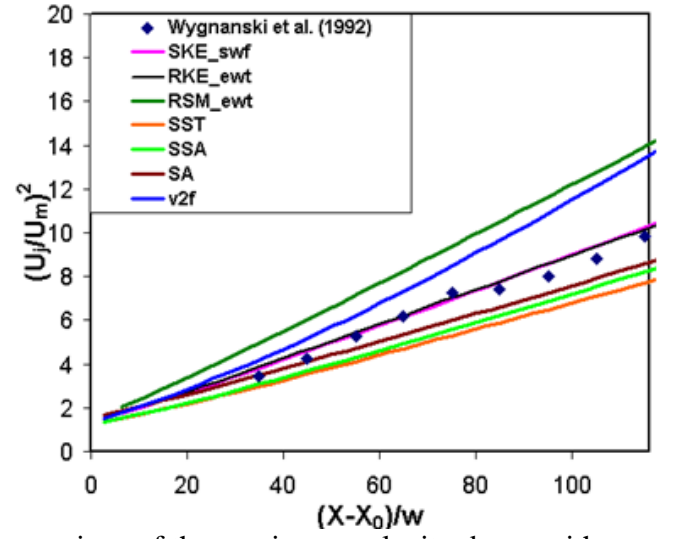

Fig 6. Comparison of the maximum velocity decay with measurements at $\operatorname{Re}=19000$.

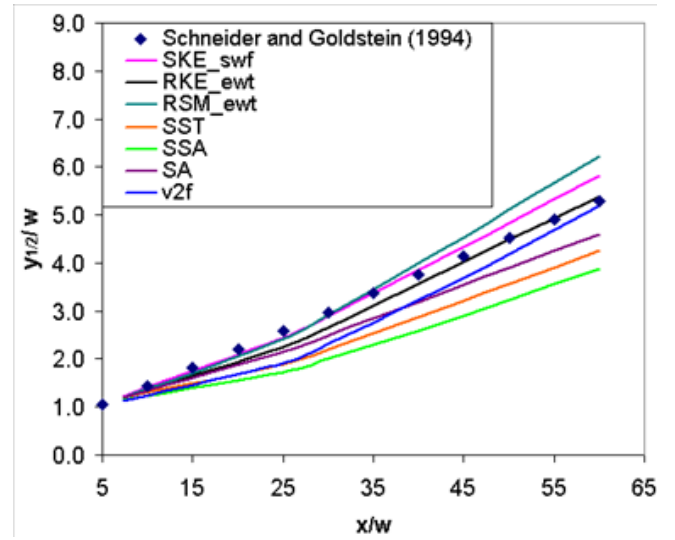

Fig 7. Comparison of jet spread rate for different models with experiment at $\mathrm{Re}=19000$.

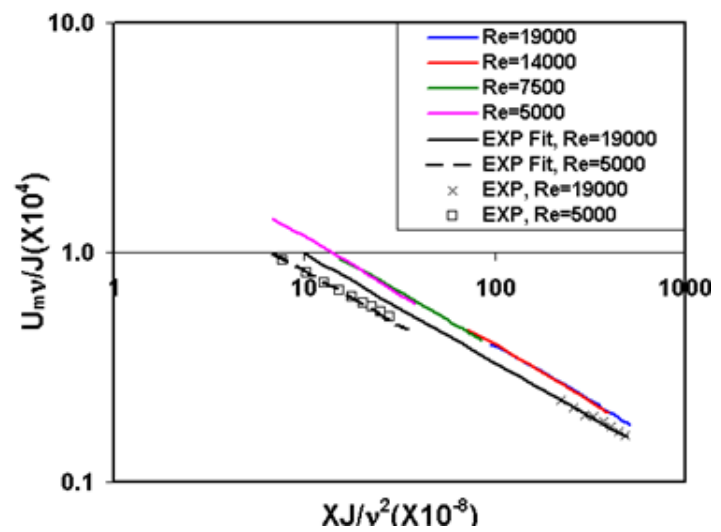

(a)

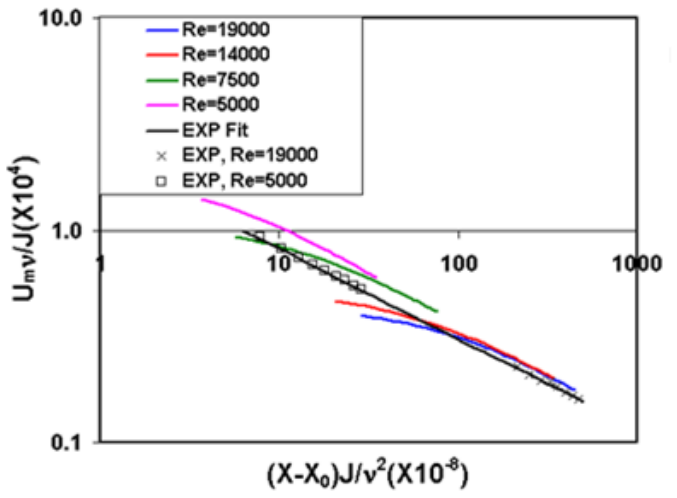

(b)

Fig 8. Comparison of normalized maximum velocity decay with data for two different length scales. 


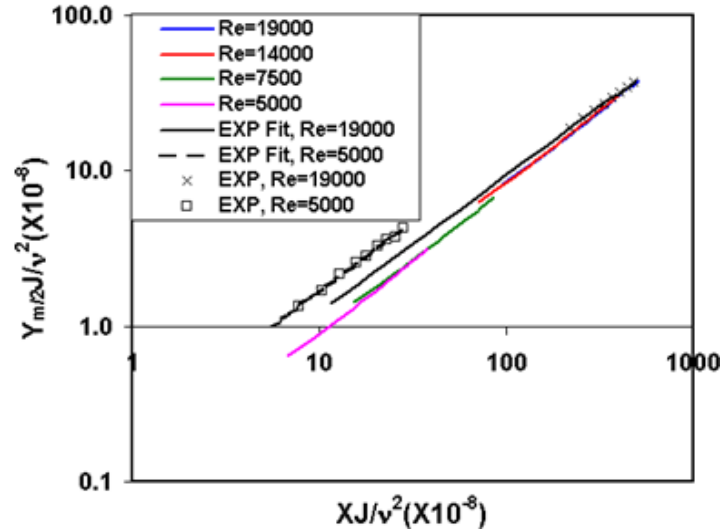

(a)

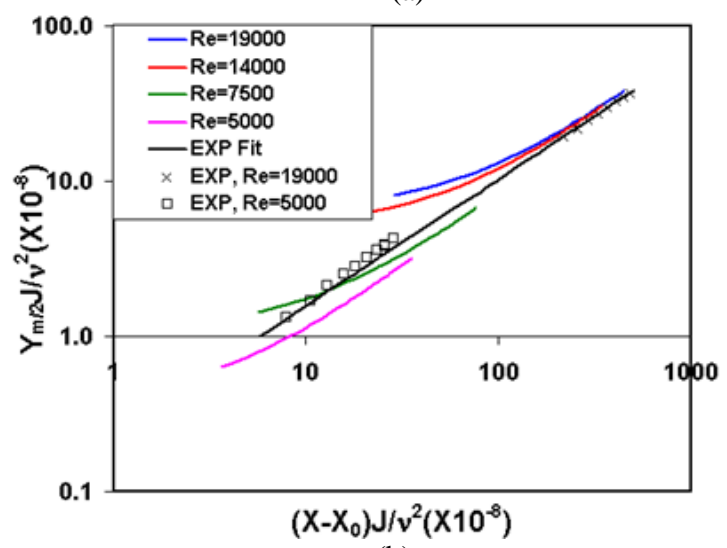

(b)

Fig 9. Comparison of jet-growth with data for two different length scales.
The difference in estimated coefficients is reflected in the Figures 8 and 9. As pointed out earlier, the virtual origin based scaling, shows a greater deviation in the maximum velocity as well as in the jet-spread rate. It has been noticed that unlike Wygnanski et al. (1992), all the models show dependency of length and velocity scales on Reynolds number with the scaling base on virtual origin.

In Table 5, the mean error in predicting the jet half widths are listed for different models. Also, in Table 5 the error in predicting the jet-spread rate is compared for different models using the two sets of experimental data. It is noticed that among the various turbulence models considered, SA shows least percentage error in predicting the jet-spread rate followed by SST and RKE_ewt. It is found that in case of SST, the RMS values in predicting the jet half width is as high as 46 as compared to that by RKE_ewt. Also, the applicability of SpalartAllmaras model is limited to non-reacting flows only. However, RKE_ewt shows better versatility when it comes to a wide range of applications where turbulent combustion processes are involved.

\subsection{Comparison of Thermal Field}

In this section comparison between predicted results using various turbulence models and the experimental data of AbdulNour et al. (2000) is presented for the thermal characteristics of wall jet. It has been observed that in terms of near field and self-similar velocity profiles, temperature field and heat transfer coefficient, none of the low Reynolds number $\mathrm{k}-\varepsilon$ model give satisfactory results. Therefore, in order to avoid clutter, only for selected models, the temperature field is compared. Subsequently, the error in prediction of heat transfer coefficient for all of the thirteen models are plotted and compared. For the sake of comparison, results using SKE with standard wall function (swf) are also shown in figures. Finally, models are ranked based on their ability to predict the heat transfer coefficient accurately.

Table 4. Comparison of correlation parameters with experimental data of Wygnanski et al. (1992) for different models

\begin{tabular}{|c|c|c|c|c|c|c|c|c|c|c|c|c|c|c|c|}
\hline \multicolumn{16}{|c|}{ Actual origin based } \\
\hline \multicolumn{2}{|c|}{ Reynolds number -> } & 5000 & 19000 & 5000 & 19000 & 5000 & 19000 & 5000 & 19000 & 5000 & 19000 & 5000 & 19000 & 5000 & 19000 \\
\hline $\mathrm{n}$ & -0.472 & -0.472 & -0.472 & -0.472 & -0.472 & -0.472 & -0.472 & -0.472 & -0.472 & -0.472 & -0.472 & -0.472 & -0.472 & -0.472 & -0.472 \\
\hline$A_{y}$ & 1.445 & 1.340 & 1.670 & 1.200 & 1.600 & 1.450 & 1.920 & 1.060 & 1.700 & 1.000 & 1.250 & 0.930 & 1.200 & 1.110 & 1.370 \\
\hline $\mathrm{m}$ & 0.881 & 0.881 & 0.881 & 0.881 & 0.881 & 0.881 & 0.881 & 0.881 & 0.881 & 0.881 & 0.881 & 0.881 & 0.881 & 0.881 & 0.881 \\
\hline$A_{u}$ & 0.557 & 0.650 & 0.560 & 0.680 & 0.560 & 0.610 & 0.480 & 0.680 & 0.500 & 0.780 & 0.640 & 0.750 & 0.620 & 0.720 & 0.620 \\
\hline $\mathrm{n}$ & -0.428 & -0.428 & -0.428 & -0.428 & -0.428 & -0.428 & -0.428 & -0.428 & -0.428 & -0.428 & -0.428 & -0.428 & -0.428 & -0.428 & -0.428 \\
\hline$A_{y}$ & 9.246 & 8.000 & 13.200 & 7.300 & 12.500 & 8.700 & 15.000 & 7.000 & 14.250 & 6.000 & 10.000 & 5.750 & 9.800 & 6.500 & 10.500 \\
\hline $\mathrm{m}$ & 0.804 & 0.804 & 0.804 & 0.804 & 0.804 & 0.804 & 0.804 & 0.804 & 0.804 & 0.804 & 0.804 & 0.804 & 0.804 & 0.804 & 0.804 \\
\hline
\end{tabular}

Table 5. Comparison of error in jet spread rate prediction for different turbulent models.

\begin{tabular}{|c|c|c|c|c|}
\hline \multicolumn{5}{|c|}{ Error in jet spread rate for different models } \\
\hline $\begin{array}{c}\text { Turbulence } \\
\text { models }\end{array}$ & $\begin{array}{c}\text { Wygnanski } \\
\text { et al. (1992) }\end{array}$ & $\%$ Error & $\begin{array}{c}\text { Schneider and } \\
\text { Goldstein (1994) }\end{array}$ & $\%$ Error \\
\hline Exp data & 0.077 & 0.0 & 0.077 & 0.0 \\
\hline SKE_swf & 0.097 & -26.4 & 0.097 & -26.3 \\
\hline RKE_ewt & 0.090 & -17.2 & 0.088 & -14.0 \\
\hline RSM_ewt & 0.109 & -41.8 & 0.096 & -24.2 \\
\hline SST & 0.068 & 11.5 & 0.074 & 3.3 \\
\hline SSA & 0.062 & 19.6 & 0.070 & 8.5 \\
\hline SA & 0.070 & 8.7 & 0.075 & 2.9 \\
\hline V2f & 0.094 & -22.0 & 0.109 & -40.9 \\
\hline
\end{tabular}

The non-dimensional temperature profiles for the isothermal plate are compared for different turbulence models at various $\mathrm{x} / \mathrm{w}$ locations in Figures 10 (a) to (c). It is seen from the Figure 10 (c) that at $\mathrm{x} / \mathrm{w}=13.02$ $v^{2}$-f model deviate maximum from the data. It has been observed that at this position with $\mathrm{AKN}$ (not shown in the figure), near wall region is captured well but beyond $\mathrm{y} / \mathrm{w}=0.03$ it shows considerable deviation from data. The SST, SA, and RKE with ewt models give equally good predictions, whereas slight over prediction has been observed using SKE with ewt. The near field region (i.e. $\mathrm{x} / \mathrm{w}=2.2$ ) is captured very well by $v^{2}$-f model, followed by SA. At this position all other models show slight under prediction.

In Figure 11, the development of thermal boundary layer is compared for different turbulence models. Non-dimensional quantities $\delta \mathrm{t} / \mathrm{w}$ and $\mathrm{x} / \mathrm{w}$ are plotted for two different values of theta of 0.1 and 0.15 in Figures 11(a) and (b) respectively. 


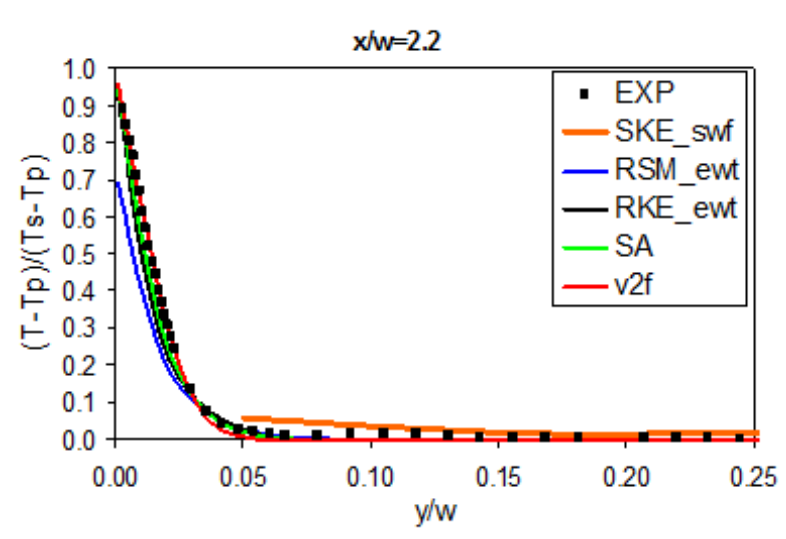

(a)

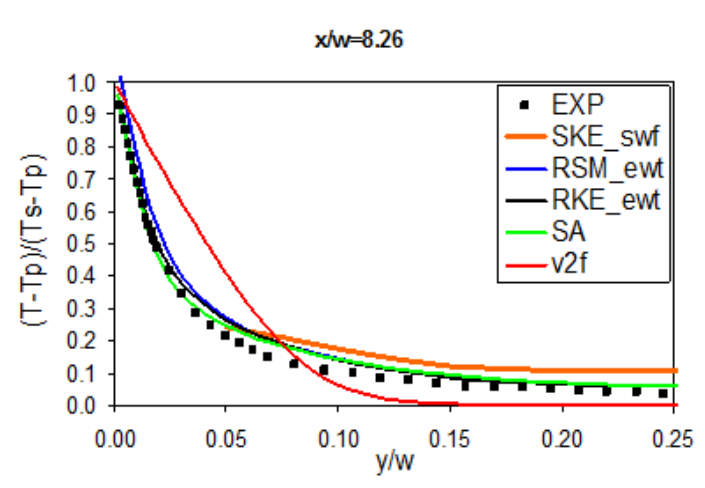

(b)

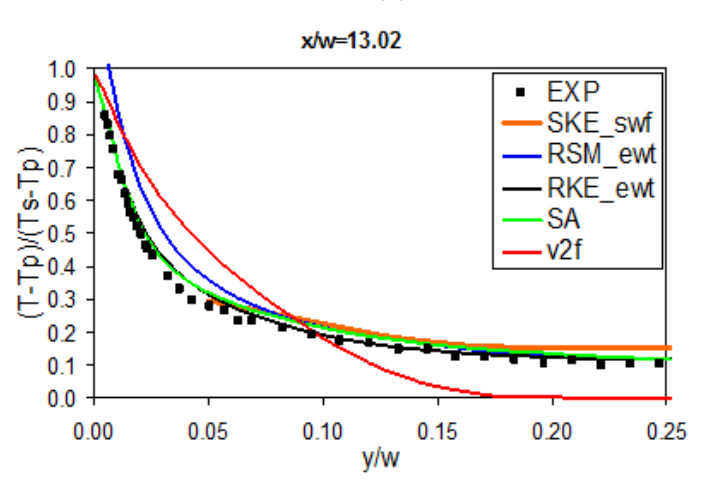

(c)

Fig 10. Comparison of temperature field for an isothermal plate with different turbulence models with the data of AbdulNour et al (2000) for $\mathrm{Re}=7700$.

The initial region (i.e. $\mathrm{x} / \mathrm{w}<8$ ), where growth of the thermal boundary layer is nonlinear, could not be captured by most of the low-Reynoldsnumber turbulence models. The prediction using YS and $v^{2}$-f models show good agreement with data, however, both of these models fail to capture change in the slope at $\mathrm{x} / \mathrm{w} \sim 8$. In this regard, realizable $\mathrm{k}-\varepsilon$ model with ewt over predicts but shows correct trends in terms of initial development and subsequent change in thermal boundary layer growth. The models of SA, SST, and RSM with ewt also show similar trends but slope change $\mathrm{x} / \mathrm{w} \sim 8$ predicted by these models is smeared.

The comparisons of heat transfer coefficient predicted by the turbulence models for uniform temperature and for uniform heat flux BCs are shown in Figures 12(a) and (b) respectively. The initial region using SKE as well as RKE with ewt is captured in the same way by both the models. However, in the further downstream, results deviate with SKE model. It is seen that increasing heat-transfer-coefficient for $\mathrm{x} / \mathrm{w} \geq 5$ and its reduction after $\mathrm{x} / \mathrm{w}>8$ could be captured well using RSM with ewt for both the cases. In this aspect the model of SA also shows good agreement with data.
Thermal B.L. for theta $=0.1$

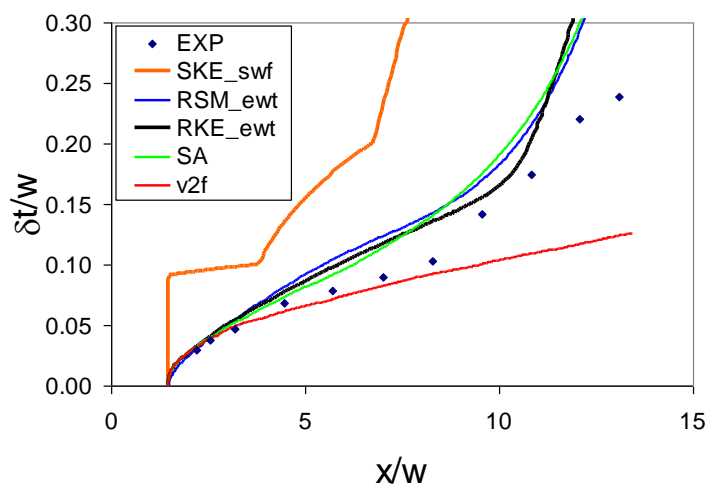

(a)

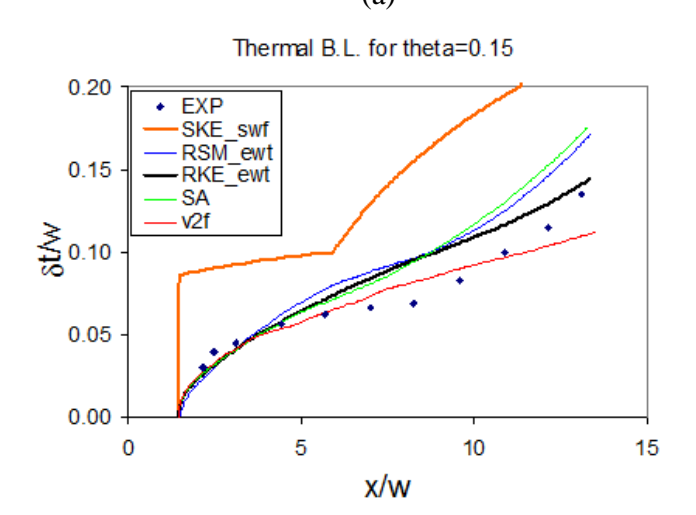

(b)

Fig 11. Comparison of thermal boundary layer for $\theta=0.1$ and $\theta=0.15$, for constant wall temperature case with the data of AbdulNour et al (2000) for $\operatorname{Re}=7700$.

The percentage errors in heat transfer coefficient for uniform temperature and for uniform heat flux BCs with different models are listed in Tables 6 . The percentage error in heat transfer coefficient is calculated by taking the average value for the region $\mathrm{x} / \mathrm{w}>6$ from Figure 12. It is seen from Table 6 that RSM with ewt gives least error in predicting the heat transfer coefficient. The error in heat transfer coefficient predicted by SSA is the second lowest, next to RSM with ewt followed by SA, RKE with ewt, and SST.

Table 6. Average errors, its standard deviation and rms errors in the heat transfer coefficient prediction by different models.

\begin{tabular}{|c|c|c|c|c|c|c|}
\hline \multirow{2}{*}{$\begin{array}{c}\text { Turbulence } \\
\text { models }\end{array}$} & \multicolumn{3}{|c|}{ Con stant heat flux BC } & \multicolumn{3}{|l|}{ Uniform temperature BC } \\
& \multicolumn{3}{|c|}{} & \multicolumn{2}{l|}{} \\
\cline { 2 - 7 } & Mean & $\sigma$ & rms & Mean & $\sigma$ & rms \\
\hline SKE_SWf & -22.0 & 1.1 & 42.3 & -67.9 & 14.0 & 84.7 \\
\hline SKE_ewt & -0.6 & 16.0 & 19.6 & 16.7 & 16.2 & 26.6 \\
\hline RKE_ewt & -10.1 & 12.0 & 22.4 & 6.6 & 13.3 & 15.5 \\
\hline V2f & 41.2 & 9.4 & 83.0 & 56.6 & 8.5 & 75.9 \\
\hline SST & -8.2 & 13.8 & 21.2 & 9.2 & 14.8 & 18.8 \\
\hline RSM_SWf & 39.9 & 4.4 & 76.0 & 37.6 & 4.3 & 4.3 \\
\hline RSM_ewt & 3.5 & 2.7 & 7.7 & 14.5 & 5.5 & 5.5 \\
\hline SA & 30.5 & 7.4 & 58.4 & 7.0 & 10.5 & 10.5 \\
\hline AKN & -4.1 & 15.9 & 20.4 & 7.7 & 24.0 & 24.0 \\
\hline Abid & -42.5 & 27.7 & 84.5 & -21.0 & 28.4 & 28.4 \\
\hline LB & -41.2 & 26.9 & 81.7 & -21.4 & 28.4 & 28.4 \\
\hline LS & -31.9 & 11.6 & 59.3 & -59.5 & 36.7 & 36.7 \\
\hline YS & 42.4 & 9.9 & 84.9 & 58.2 & 8.2 & 8.2 \\
\hline CHC & -38.2 & 27.1 & 76.8 & -17.5 & 27.5 & 27.5 \\
\hline SSA & 18.3 & 14.0 & 81.7 & -6.9 & 22.4 & 22.4 \\
\hline
\end{tabular}


Heat transfer coefficient for constant temperature B.C.

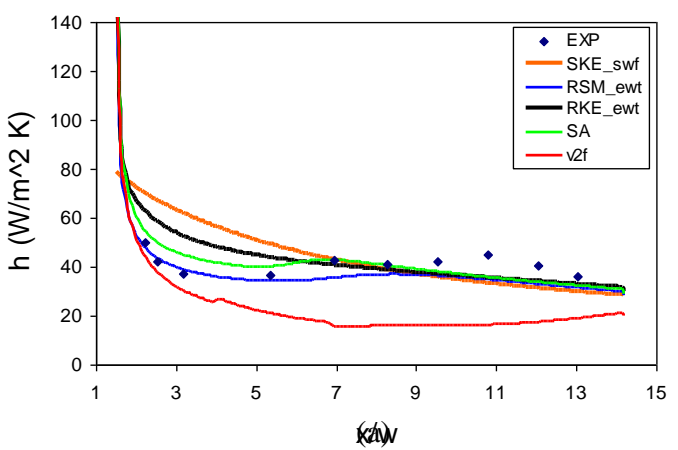

Heat transfer coefficient for constant heat flux B.C.

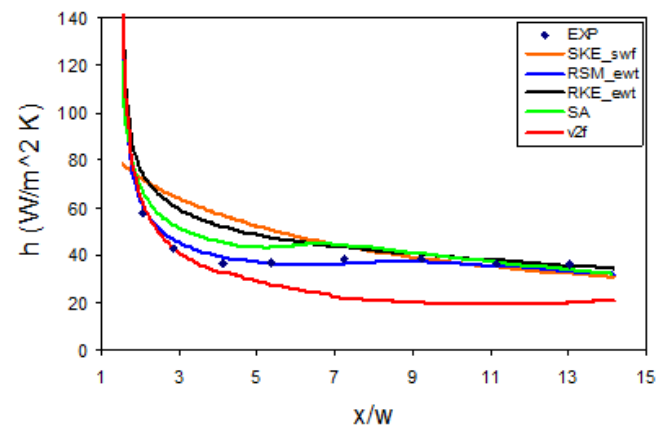

(b)

Fig 12. Comparison of local heat transfer coefficient for isothermal and isoflux boundary conditions with the data of AbdulNour et al (2000) for $\operatorname{Re}=7700$.

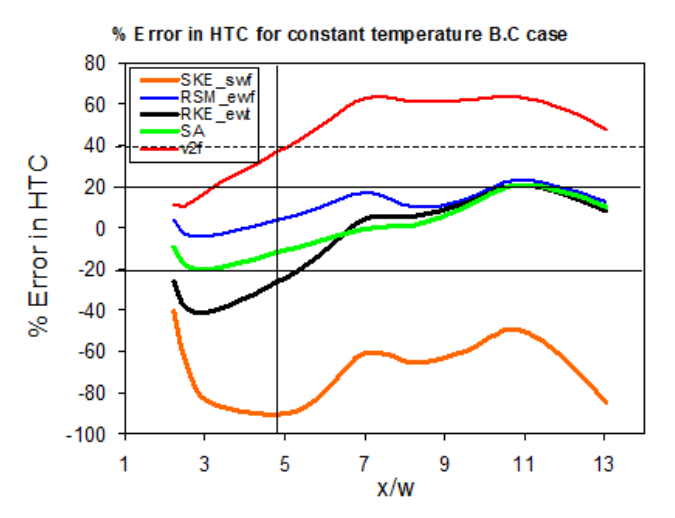

(a)

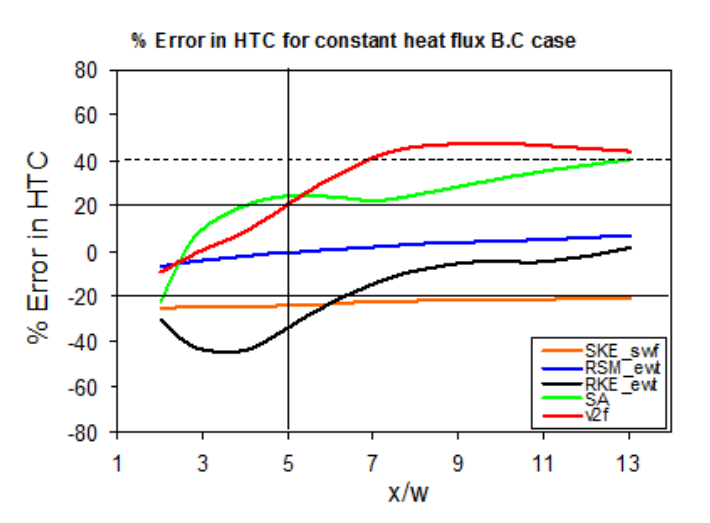

(b)

Fig 13. Comparison of error bands and selection criteria for the best turbulence models.
Figures 13(a) and (b) show the axial variation error in heat transfer coefficient plotted separately for uniform temperature and constant heat flux cases, respectively. For gas turbine combustor liners, accurate predictions beyond $\mathrm{x} / \mathrm{w}>5$ are very important to correctly estimate film-cooling effectiveness. Therefore, models are categorized for \pm 20 and 40 percent accuracy in predicting the heat transfer coefficient. It is seen from Figure 13(a) and (b) that only RSM with ewt could satisfy the requirement of \pm 20 percent error band for constant heat flux as well as uniform temperature cases. On the other hand, for the allowable error band of \pm 40 percent, apart from RSM with ewt there are four models, namely SA, SST, and RKE and SKE with ewt, which satisfy this requirement. Also, it is seen that beyond $\mathrm{x} / \mathrm{w}>5$ the percentage error for RSM, SA and RKE with ewt falls between $0-10 \%$, which is within the experimental uncertainty of around $10 \%$ reported by AbdulNour et al. (2000). The computational time required for RSM is substantially higher than that of the other RANS models. Therefore, the models of SA and RKE with ewt offer a better option when both accuracy and computational time are taken into consideration. These two models show consistently accurate predictions for both the velocity and thermal field. In case of gas turbine combustor, since flow field is much more complex, the RKE with ewt would be the preferred choice over the SA model.

\section{SUMMARY AND CONCLUSIONS}

In the present study, emphasis is laid upon the accurate prediction of heat transfer and flow field characteristics of heated wall jet flows in order to earmark a suitable turbulence model. To achieve this, the results of thirteen turbulence models, implemented in ANSYS FLUENT are compared against the experimental data of Wygnanski et al. (1992), and Schneider and Goldstein (1994) for the cold wall jet configuration and against the data of AbdulNour et al. (2000) for heated wall jet configuration. It is seen that only a few of these models could accurately capture the complex flow features of the wall jet. The performance of the models for flow field characteristics like maximum velocity decay and jet spread rate been compared with the experimental measurements of Wygnanski et al. (1992) using the length scale as virtual origin. None of the models is found to show Reynolds number independence for length scale based on virtual origin. The near wall velocity profile captured using Realizable k- $\varepsilon$ (RKE) with enhanced wall treatment (ewt) shows the best agreement with the experimental data as compared to the other models. The spread rate of the jet is an important parameter that singles out the model, which can predict the flow field of the heated wall jet correctly. The model of SpalartAllmaras is found to capture most of the flow features well but its applicability is limited to only non-reacting flows. The shear stress transport (SST) and Sarkar \& So (SSA) models do well in predicting jet spread rate but lack consistency in predicting other flow features like jet half width accurately. The Spalart Allmaras (SA), Reynolds Stress Model (RSM) and Realizable k- $\varepsilon$ (RKE) with enhanced wall treatment (ewt) are the models, which also satisfy this requirement. For the heated wall jet configuration of AbdulNour et al. (2000), considerable deviation has been observed using standard k- $\varepsilon$ (SKE) with standard wall function (swf) whereas that of $v^{2}$-f shows good prediction of temperature profiles in the near field region. However, the $v^{2}$-f model is found to deviate from the data in the downstream region where the velocity profiles exhibit similarity. In the prediction of heat transfer coefficient, RSM followed by SA and RKE with ewt, is found to be the closer to the experimental data compared to the rest of the models. The computational time required for RSM is substantially higher than that of the other RANS models. Therefore, RKE with ewt would be the best choice among various turbulence models to capture the complex flow physics of heated wall jets with least computational time required. 


\section{NOMENCLATURE}

Ui Velocity tensor

$\frac{\mathrm{P}}{u_{i} u_{i}} \quad$ Pressure

$u_{i} u_{j} \quad$ Turbulent stress tensor

k Kinetic energy

$\mathrm{Pk} \quad$ Production of kinetic energy

$\varepsilon \quad$ Dissipation rate

$\mathrm{f1}, \mathrm{f2}$ Damping functions in the ' $\varepsilon$ ' equation.

$\mathrm{D}, \mathrm{E} \quad$ Addition terms in the K- $\varepsilon$ turbulence model.

$\mathrm{C} \varepsilon_{1}, C \varepsilon_{2}$ Constants in the $\mathrm{K}-\varepsilon$ equation.

$\mathrm{S}_{\mathrm{ij}} \quad$ Strain rate tensor

$v_{\mathrm{t}} \quad$ Turbulent kinematic viscosity

$\mu_{\mathrm{t}} \quad$ Turbulent dynamic viscosity

$\ell \quad$ Length scale

Re Reynolds number

$\mathrm{H} \quad$ Slot height width

SA Spalart Allmaras

SKE Standard k- $\varepsilon$

RKE Realizable k- $\varepsilon$

RSM Reynolds stress mode

SST Shear-stress transport

Ewt Enhanced wall treatment

Swf standard wall function

\section{ACKNOWLEDGEMENTS}

The authors would like to express their sincere gratitude to Professor Hukam C. Mongia at Purdue University for his collaboration and mentorship during the course of this work. The authors would like to appreciate the efforts of Mr. Subashish Battacharjee and Ms. Savithiri for their help in preparing the manuscript.

\section{REFERENCES}

AbdulNour, R.S., Willenborg, K., McGrath, J.J., Foss, J.F., and AbdulNour, B.S., 2000, "Measurements of the convective heat transfer coefficient for a planar wall jet: uniform temperature and uniform heat flux boundary conditions," Experimental Thermal and Fluid Science, 22(3-4), 123-131.

http://dx.doi.org/10.1016/S0894-1777(00)00018-2

Abe, K., Kondoh, T., and Nagano, Y., 1994, "A new turbulence model for predicting fluid flow and heat transfer in separating and reattaching flows - I. flow field calculations," International Journal of Heat and Mass Transfer, 37(1), 139-151.

http://dx.doi.org/10.1016/0017-9310(94)90168-6

Abid, R., 1991, "A two-equation turbulence model for compressible flows," Technical Report AIAA-91-1781, AIAA 22nd Fluid Dynamics, Plasma Dynamics and Lasers Conference, Honolulu, Hawaii.

ANSYS Fluent 6.3, documentations.

ANSWER user's manual, version 4.00, 1999, Rev. C, Analytic and Computational Research, Inc. (ACRi), 1931 Stradella Rd, Bel Air, CA, 90077.

Chang, K.C., Hsieh, W.D., and Chen, C.S., 1995, "A modified lowReynolds-number turbulence model applicable to recirculating flow in pipe expansion," ASME Journal of Fluids Engineering, 117(3), 417423.

http://dx.doi.org/10.1115/1.2817278

Chen, H.C., and Patel, V.C., 1988, "Near-wall turbulence models for complex flows including separation," AIAA Journal, 26(6), 641-648. http://dx.doi.org/10.2514/3.9948
Durbin, P.A., 1991, "Near-wall turbulence closure modeling without damping functions," Theoretical Computational Fluid Dynamics, 3(1), $1-13$. http://dx.doi.org/10.1007/BF00271513

Eriksson, J.G., Karlsson. R.I., and Persson, J., 1998, “An experimental study of a two-dimensional plane turbulent wall jet," Experiments in Fluids, 25(1), 50-60. http://dx.doi.org/10.1007/s003480050207

Gerodimos, G., and So, R.M.C., 1997, "Near-wall modeling of plane turbulent wall jets," Transactions of the ASME Journal of Fluids Engineering, 119(2), 304-313. http://dx.doi.org/10.1115/1.2819135

Kumar, G.N., and Mongia, H.C., 1999, "Validation of Turbulence models for wall jet computations as applied to combustor liners," AIAA-1999-2250, 35 ${ }^{\text {th }}$ AIAA/ASME/ASEE Joint Propulsion Conference, Los Angeles, California.

Kumar, G.N., and Mongia, H.C., 2000, "Validation of Near Wall Turbulence models for Film Cooling Applications in Combustors," AIAA-2000-0480, $38^{\text {th }}$ AIAA Aerospace Sciences Meeting, Reno, NV.

Lam, C.K.G., and Bremhorst, K., 1981, "A modified form of the kepsilon model for predicting wall turbulence," ASME Journal of Fluids Engineering, 103, 456-460.

http://dx.doi.org/10.1115/1.3240815

Launder, B.E., and Spalding, D.B., 1972, "Lectures in mathematical models of turbulence," Academic Press, London, England.

Launder, B.E., and Spalding, D.B., 1974, "The numerical computation of turbulent Flows," Computer Methods in Applied Mechanics and Engineering, 3(2), 269-289.

http://dx.doi.org/10.1016/0045-7825(74)90029-2

Launder, B.E., and Sharma, B.I., 1974, "Application of the energydissipation model of turbulence to the calculation of flow near a spinning disc," Letters in Heat Mass Transfer, 1(2), 131-138.

http://dx.doi.org/10.1016/0094-4548(74)90150-7

Launder, B.E., Reece, G.J., and Rodi, W., 1975, "Progress in the development of a Reynolds-Stress turbulence closure," Journal of Fluid Mechanics, 68(3), 537-566.

http://dx.doi.org/10.1017/S0022112075001814

Launder, B.E., and Rodi, W., 1979, “The turbulent wall jet,” Progress in Aerospace Sciences, 19(2-4), 81-128. http://dx.doi.org/10.1016/0376-0421(79)90002-2

Menter, F.R., 1994, "Two-equation eddy-viscosity turbulence models for engineering applications," AIAA Journal, 32(8), 1598-1605. http://dx.doi.org/10.2514/3.12149

Narasimha, R., Narayan, K.Y., and Parthasarathy, S.P., 1973, "Parametric analysis of turbulent wall jets in still air," Aeronautical Journal, 77, pp 355-359.

Parneix, S., and Durbin, P., 1997, "Numerical simulation of 3D turbulent boundary layers using the $\mathrm{V}^{2}-\mathrm{F}$ model," Annual Research Briefs, Center for Turbulence Research, NASA Ames/Stanford Univ. 135-148.

http://airex.tksc.jaxa.jp/pl/dr/19990063260/en

Sarkar, A. and So, R.M.C., 1997, "A critical evaluation of near-wall two-equation models against direct numerical simulation," International Journal of Heat and Fluid Flow, 18(2), 197-208. http://dx.doi.org/10.1016/S0142-727X(96)00088-4 
Schneider, M.E., and Goldstein, R.J., 1994, "Laser Doppler measurement of turbulence parameters in a two-dimensional plane wall jet," Physics of Fluids, 6 (9), 3116-3129.

http://dx.doi.org/10.1063/1.868136

Shih, T.H., Liou, W.W., Shabbir, A., Yang, Z., and Zhu, J., 1994, “A new k-epsilon eddy viscosity model for high Reynolds number turbulent flows: Model development and validation," Computers and Fluids, 24(3), 227-238

http://dx.doi.org/10.1016/0045-7930(94)00032-T

Spalart, P.R., and Allmaras, S.R., 1992, "A one-equation turbulence model for aerodynamic flows," Proceedings of the 30th AIAA Aerospace Sciences Meeting and Exhibit, 92(2). http://dx.doi.org/10.1051/meca:2007025
Wolfshtein, M., 1969, "The velocity and temperature distribution in one-dimensional flow with turbulence augmentation and pressure gradient," International Journal of Heat and Mass Transfer, 12(3), 301318.

http://dx.doi.org/10.1016/0017-9310(69)90012-X

Wygnanski, I., Katz, Y., and Horev, E., 1992, "On the applicability of various scaling laws to the turbulent wall jet," Journal of Fluid Mechanics, 234, 669-690.

http://dx.doi.org/10.1017/S002211209200096X

Yang, Z., and Shih, T.H., 1993, "New Time Scale Based k-epsilon model for near wall turbulence," AIAA Journal, 31(7), 1191-1198. http://dx.doi.org/10.2514/3.11752 